\section{ÓPERA, RAÇA E GÊNERO SOB O PONTO DE VISTA DE ARTISTAS NEGRAS(OS)}

RevistaMúsica | vol. 19, n.2 | pp. 149-172 | jul. 2019

\section{Antonilde Rosa Pires}

nildeantoniufrjmestrado@gmail.com I UFRJ

\section{Andréa A. Adour da Câmara}

andreaadour@musica.ufrj.br| UFRJ

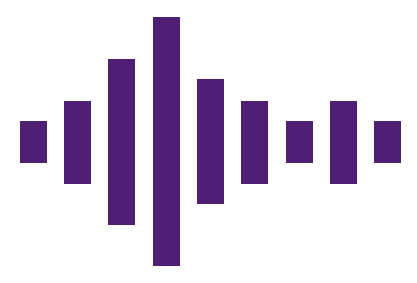

OPERA, RACE AND

GENRE FROM THE POINT OF VIEW OF BLACK ARTISTS

Recebido em: 18/05/2019

Aprovado em: 29/06/2019

\section{RESUMO}

Esta proposta se configura em um ensaio teórico sobre ópera, raça e gênero a partir do ponto de vista de artistas negras(os).

Para o embasamento das reflexões temos como referencial teórico autores que estudam sobre a temática, como por exemplo a musicóloga Naomi André no livro Black Opera: History, Power, Engagement. Compreende-se que, esta proposta é fundamental para construção de debates mais amplos para se tratar de protagonismos de compositoras(es) e artistas negras(os), bem como em uma contranarrativa àquilo que Lélia Gonzales chama da "neurose cultural". Esta reflexão é relevante para se desnaturalizar estereótipos sobre intelectuais e artistas negras(os).

\section{PALAVRAS-CHAVE:}

Ópera; Raça; Gênero; Compositoras(es); Negras(os).

\section{ABSTRACT}

This proposal is configured in a theoretical essay about opera, race and gender from the point of view of black artists. For the basis of the reflections we have as theoretical reference authors who study on the theme, like the musicologist Naomi André in the book Black Opera: History, Power, Engagement. It is understood that this proposal is fundamental for the construction of broader debates to address the

prominence of black composers and artists, which are constituted as a counter-narrative to what Lélia Gonzales calls the "cultural neurosis". This reflection is relevant to denaturalize stereotypes about black intellectuals and artists.

KEYWORDS:

Opera; Race; Gender; Composers; Black People. 


\title{
ÓPERA, RAÇA E GÊNERO SOB O PONTO DE VISTA DE ARTISTAS NEGRAS(OS)
}

\author{
Antonilde Rosa Pires \\ nildeantoniufrjmestrado@gmail.com | UFRJ \\ Andréa A. Adour da Câmara \\ andreaadour@musica.ufrj.br | UFRJ
}

\section{Introdução}

Locus social é o lugar onde um determinado grupo está localizado e de onde se posiciona, tece suas articulações ideológicas, políticas e culturais. É importante destacar que o locus social em que os diversos grupos étnicos/raciais brasileiros estão posicionados não se trata de algo inerente a estes. Estes lugares foram definidos pela macroestrutura colonizatória, a partir do discurso civilizatório que afere a lógica dicotômica entre grupos supostamente "superior" e "inferior", "culto" e "inculto", etc. Tudo isso opera especialmente para a promoção da desigualdade racial e, consequentemente, social.

Locus social é um termo cooptado pelos movimentos sociais como sinônimo de Lugar de fala. As ativistas dos feminismos atualmente formam o grupo que mais tem se debruçado a estudar, sistematizar e transformar o conceito em um campo epistêmico e metodológico para os estudos que buscam compreender os processos de construção da subalternização. As teóricas do feminismo negro são as que assumem protagonismos da temática, articulando com estudos das questões raciais, de gênero, e sobre a subalternização da mulher negra nos Estados Unidos, América Latina e outros continentes.

Aqui no Brasil a filósofa e feminista Djamila Ribeiro publicou o livro O que é lugar de fala?, no qual ela desenvolve não somente uma sistematização acerca da definição do conceito, mas, principalmente: "busca-se aqui, sobretudo, lutar para romper com o regime de autorização discursiva" (RIBEIRO, 2017, p. 70). Ela destaca que o intuito é refletir sobre como as experiências compartilhadas pelas mulheres negras podem revelar condições sociais que descortinam opressões e mazelas do modus operandi da estrutura hierarquizada entre os grupos raciais e sociais. O foco aqui, é ressaltar a importância de debate sobre locus social dentro das dinâmicas das relações de controle e poder.

O lugar social não determina uma consciência discursiva sobre esse lugar. Porém o lugar que ocupamos socialmente nos faz ter experiências distintas e outras perspectivas. A teoria do ponto de vista feminista e lugar de fala nos faz refutar uma visão universal de mulher e de negritude, e outras identidades, assim como faz com que homens brancos, que se pensam universais, se racializem, 
entendam o que significa ser branco como metáfora de poder, como nos ensina Kilomba (RIBEIRO, 2017, p. 70).

Trazer essa concepção para este ensaio é uma estratégia para apresentar também as dinâmicas e ações de enfrentamento que artistas negras realizam para conter os processos de invisibilização. Significa também refutar as histórias únicas sobre as mulheres negras e possibilitar outros caminhos para a produção de conhecimento, que possam trazer as mulheres negras à disputa não somente de narrativas e discursos, mas, principalmente, à inserção nos espaços de poder.

\section{2. Ópera e Locus social}

Locus social é uma das questões centrais para as abordagens desenvolvidas aqui, já que propomos uma reflexão a partir da perspectiva de artistas negras e negros no campo operístico. Uma das referências é a musicóloga Naomi André, professora do Departamento de Música e dos Estudos da Mulher do Departamento de Estudos AfroAmericanos e Africanos da Faculdade Residencial da Universidade de Michigan. No livro Black Opera: History, Power, Engagement ela tece reflexões sobre o campo operístico dentro de uma linearidade onde o passado faz a ponte para compreendermos o presente. A ópera é utilizada como instrumento para o desenvolvimento de uma abordagem crítica, bem como ferramenta de ativismo político e mudança social. André aponta as novas bases para abordagens no campo da erudição aplicada.

\footnotetext{
No meu estudo, eu li a voz dos criadores, artistas e audiências da ópera em um modo integrativo inspirado em Freire. Eu não categorizo toda a ópera como exemplos ultrapassados de um gênero irrelevante que fala apenas para plateias ocidentais europeias brancas. Fazer isso tanto simplificaria quanto negaria os tesouros artísticos da civilização ocidental a pessoas não-brancas, devido apenas a uma diferença científica percebida baseada na cor da pele, um marcador visual enganoso que não tem base científica. Como gênero, a ópera não é necessariamente falsa com os estereótipos negativos machistas do racismo. Em vez disso, funciona como um porta-voz, um canal através do qual um reflexo da ideologia cultural de uma sociedade - que pode incluir esses estereótipos - pode ser ouvido e visto (ANDRÉ, 2016, p. 196).
}

Naomi Andre constrói suas observações a partir do conceito formulado por Patricia Hill Collins (2000) sobre o ponto de vista das mulheres negras, conhecido como "black woman's standpoint”. Estas teorias sistematizam as experiências racializadas e de gênero, dentro de uma perspectiva ilustrativa das formas como as pessoas que compartilham uma mesma vivência social de forma que promovam o empoderamento, capacitam a consciência coletiva e a ação política de seus grupos de pertencimento. Naomi André pondera que grupos historicamente marginalizados estabelecem relações 
interativas com a cultura dominante e, ao mesmo tempo em que isso pode ser prejudicial, pode ser também libertador. Ela também se inspira em Educação para a Consciência Crítica, de Paulo Freire, para dialogar, tanto com o conceito de "integração" dentro de um contexto que se estrutura diante de um sistema democrático flexível, formulado por pensamento crítico, quanto com o de "adaptação", relacionado a uma postura mais passiva. Este diálogo é capaz de propiciar a compreensão do Modus operandi das estruturas opressivas, para que pessoas de grupos marginalizados possam reagir à cultura dominante.

A musicóloga destaca as estratégias que artistas e compositores afro-americanos e sul-africanos construíram para utilizar a ópera como forma de ressignificar e reposicionar negras e negros na história e na sociedade. Para a autora, a ópera se configura em uma força cultural, política e com um poder transformador ou mesmo libertador. Ela afirma que seu estudo é atravessado pela sua condição de mulher negra e experiência de gênero e raça.

A socióloga Lélia Gonzalez, em Racismo e sexismo na cultura brasileira, pontua que as trajetórias das mulheres negras são marcadas pelas experiências consequentes das engrenagens do maquinário da escravidão, do racismo e da colonização europeia. Para ela, as experiências das mulheres negras se diferenciam das hegemônicas por causa das articulações das categorias sociais de raça, sexo e classe.

\footnotetext{
O lugar em que nos situamos determinará nossa interpretação sobre o duplo fenômeno do racismo e do sexismo. Para nós o racismo se constitui como a sintomática que caracteriza a neurose cultural brasileira. Nesse sentido, veremos que sua articulação com o sexismo produz efeitos violentos sobre a mulher negra em particular. Consequentemente, o lugar de onde falaremos põe um outro, aquele que habitualmente nós vínhamos colocando em textos anteriores. E a mudança foi se dando a partir de certas noções que, forçando sua emergência em nosso discurso, nos levaram a retornar a questão da mulher negra numa outra perspectiva (GONZALES, 1984, p. 224).
}

\section{Racismo patriarcal heteronormativo}

Às perspectivas citadas anteriormente será acrescentado o conceito de Racismo patriarcal heteronormativo, uma abordagem particular do racismo proposta pelas intelectuais negras contemporâneas Werneck e Nilza Iraci. O termo, segundo as autoras em seu Dossiê Mulher Negra, "é um modo de unir o racismo atuante no Brasil e seus modos de atuação diferenciada a partir do sexismo e das fobias LGBT". Elas enfatizam também que:

O conceito permite chamar atenção para os diferentes processos que atuam na produção da subordinação de indivíduos e grupos, jogando luz ao fenômeno denominado de interseccionalidade. 
Sob o racismo patriarcal heteronormativo, processos de subordinação, violência e inferiorização das pessoas negras adquire ferramentas que atingem de forma específica todas as que se situam em posições femininas dentro do espectro das identidades de gênero (WERNECK, IRACI, s/d, p. 11).

Para as autoras, o debate sobre a situação da mulher negra dentro da visão restrita ao capitalismo patriarcal é negligenciado, uma vez que este movimento não reconhece a opressão de caráter racial e se sustenta no mito da democracia racial e da miscigenação. Tais discursos não são mais que argumentos falaciosos, com intuito de silenciar os debates sobre as opressões e desigualdades raciais no Brasil.

Para desenvolvermos as reflexões sobre as questões raciais aqui neste estudo, abordamos as três dimensões do escopo do racismo na sociedade brasileira que são: individual, institucional e estrutural. A primeira diz respeito à maneira como o indivíduo constrói sua subjetividade ao interagir com o racismo; a segunda indica como as instituições públicas e privadas se relacionam e operam dentro da lógica e dos princípios orientados pela raça - gerando violências e discriminações; enquanto a terceira trata das ações e relações estabelecidas dentro do contexto econômico-capitalista. O filósofo e advogado Silvio Almeida, em O que é racismo estrutural?, apresenta os conceitos dessas três concepções de racismo. Sobre o racismo individual ele discorre:

\footnotetext{
Seria um fenômeno ético ou psicológico de caráter individual ou coletivo, atribuído a grupos isolados; ou ainda, a uma "irracionalidade", a ser combatida no campo jurídico por meio de aplicação de sanções civis - indenizações, por exemplo - ou penais. Por isso, a concepção individualista pode não admitir a existência de "racismo", mas somente de "preconceito", a fim de ressaltar a natureza psicológica do fenômeno em detrimento de sua natureza política (ALMEIDA, 2018, p. 28).
}

Ele pondera que, para o enfrentamento desta natureza de racismo, algumas ações podem ajudar no desenvolvimento de práticas que estimulam e propiciam mudanças culturais. Tais ações podem ser desenvolvidas no âmbito educacional, para o processo de conscientização dos aspectos criminosos e da responsabilização daqueles que praticam tais crimes. O filósofo sublinha também as fragilidades e limitações quando o racismo individual é posicionado como base da análise, porque a ele é sempre atribuído uma conotação moralista e comportamental, excluindo assim, as dimensões políticas e econômicas que aprisionam a população negra na marginalidade social.

Em relação ao racismo institucional, Almeida faz observações sobre as práticas estabelecidas em relações às estruturas de poder. "Sob esta perspectiva, o racismo não se resume a comportamentos individuais, mas é tratado como o resultado do funcionamento das instituições que passam a atuar em uma dinâmica que a confere, ainda que indiretamente, desvantagens e privilégios a partir da raça." (ALMEIDA, 2018, 
p. 29). O racismo institucional se configura uma vez que os conflitos raciais estruturam os regimentos das instituições. Ele possibilita a ampliação das desigualdades raciais para além do âmbito individual. Segundo o autor:

\begin{abstract}
As instituições reproduzem as condições para o estabelecimento e a manutenção da ordem social. Desse modo, se é possível falar de um racismo institucional, significa que, de algum modo, a imposição de regras e padrões racistas por parte da instituição é de alguma maneira vinculada à ordem social que ela visa resguardar. Assim como a instituição tem sua atuação condicionada a uma estrutura social previamente existente com todos os conflitos que lhes são próprios, o racismo que esta instituição expressa é também parte desta mesma estrutura. As instituições são apenas a materialização de uma estrutura social ou de um modo de socialização que tem o racismo como um de seus componentes orgânicos. Dito de modo mais direto: as instituições são racistas porque a sociedade é racista (ALMEIDA, 2018, p. 36).
\end{abstract}

Para Almeida, as instituições não criam o racismo, apenas o reproduzem. "O racismo é parte da ordem social" (ALMEIDA, 2018, p. 36). Esta citação nos faz lembrar de algumas questões relacionadas ao discurso de "ordem" como instrumento de opressão e mantenimento de privilégios. Ele ilustra as hegemonias de determinados grupos raciais dentro das instituições e a consolidação de seus projetos de interesses políticos e econômicos. Sendo assim, para a autor, racismo institucional trata de poder como base da relação racial. Logo, racismo é sinônimo de dominação. Sobre a terceira e última concepção de racismo abordada aqui, ela destaca:

\footnotetext{
O racismo é uma decorrência da própria estrutura social, ou seja, do modo "normal" com que se constituem as relações políticas, econômicas, jurídicas e até familiares, não sendo uma patologia social e nem um desarranjo institucional. O racismo é estrutural. Comportamentos individuais e processos institucionais são denominados de uma sociedade cujo racismo é regra e não exceção. $\mathrm{O}$ racismo é parte de um processo social que ocorre pelas costas dos indivíduos e lhes parece legado pela tradição. Nesse caso, além de medidas que coíbam o racismo individual e institucional, torna-se imperativo refletir sobre mudanças profundas nas relações sociais, políticas e econômicas (ALMEIDA, 2018, pp. 38-39).
}

Para Silvio Almeida, a organização política, econômica e jurídica é o principal meio de propagação do sistêmica de práticas racistas. É por isso que o racismo acontece de forma real dentro do contexto das desigualdades nesses aspectos. Porém, o fato de o racismo ser estrutural não implica em que ele seja irreversível ou as pautas antirracistas insignificantes e, tampouco, que pessoas racistas não sejam julgadas por isso. Não criar medidas e estratégias de romper com o racismo significa desqualificar a dimensão social, histórica e políticas das violações e violências de tal estrutura. Segundo Almeida, "o que queremos enfatizar do ponto de vista teórico, é que o racismo, como processo histórico e 
político, cria as condições sociais para que, direta ou indiretamente, grupos racialmente identificados sejam discriminados de forma sistemática” (ALMEIDA, 2018, p. 39).

Ou seja, o que o filósofo salienta é que há uma relação de retroalimentação entre o racismo individual, institucional e estrutural, e, por isso, os estudos que pautam a temática das relações raciais com foco no racismo, necessariamente devem abordar seu escopo conceitual. Nem um deles deve ser negligenciado ou diminuído nas análises, já que estabelecem relações de dependência entre si. Ele enfatiza que os estudos acerca do racismo estrutural consideram a condição do indivíduo racializado dentro das engrenagens de um sistema que, além de possibilitar as práticas, cria e recria recursos estruturantes do racismo.

Ele enfatiza a importância do desenvolvimento de observações mais complexas sobre a questão racial para evitar inferências superficiais que nada contribuem na pauta antirracista.

\footnotetext{
Pensar o racismo como parte da estrutura não retira a responsabilidade individual sobre as práticas de condutas racistas e não é um álibi para racistas. Pelo contrário; entender que o racismo é estrutural, e não um ato isolado [...] nos torna ainda mais responsáveis pelo combate ao racismo e aos racistas (ALMEIDA, 2018, p. 40).
}

Partindo dessa perspectiva sobre o escopo do racismo, o debate sobre as questões raciais aqui neste trabalho abarca essas três perspectivas.

\section{Reflexões teóricas e musicológicas}

As reflexões desenvolvidas anteriormente nos apontam a necessidade de construir outras narrativas e considerar outros saberes para que possamos fugir de uma epistemologia universal que opera como um instrumento de legitimação e imposição do saber dominante. Práticas conservadoras ainda se apresentam de forma enraizada no campo da musicologia contemporânea. Vale dizer que, embora o campo venha apresentando mudanças significativas em prol do respeito às singularidades, mesmo assim ainda visualizamos propostas defensoras de uma prática musicológica que mantêm o status quo instituído. Um defensor deste modelo é o musicólogo Giles Hooper.

Em seu livro The discourse of musicology, em especial no capítulo A New Musicology, Hooper faz uma série de críticas sobre os estudos pós-modernos e feministas. Neste caso, o meu interesse é estabelecer um breve diálogo com suas críticas aos estudos feministas. No tópico Gênero do referido capítulo, Hooper inicia a sua crítica a partir da seguinte problematização: 
Meu objetivo nesta seção [...] focalizar uma questão muito precisa: até que ponto uma preocupação com "gênero", ou "representação de gênero", pode justificadamente ser considerado um desenvolvimento inerentemente "novo", "crítico" ou mesmo "pós-moderno" (HOOPER, 2006, p. 30).

Esta questão que o autor levanta, por si só, já é passiva de desconfiança acerca da profundidade do conhecimento que o musicólogo apresenta sobre a temática. A primeira desconfiança aparece devido ao fato de o autor tratar tanto o Pós-modernismo quanto o Feminismo de forma generalizada, reducionista e superficial, como se se tratassem de fenômenos homogêneos e unilaterais. Uma breve pesquisa na literatura dos estudos pósmodernos e de gênero já nos permite visualizar as diversas correntes, disputas e tensões. Em relação ao feminismo temos: Feminismo Negro, Feminismo Interseccional (pósmoderno), Feminismo Radical, Feminismo Liberal, Transfeminismo, Feminismo Marxista, Feminismo Lésbico ou Lesbofeminismo, Feminismo Anarquista, Anarcofeminismo ou Feminismo libertário, Feminismo Indígena, Feminismo Asiático, dentre outras.

Sobre a complexidade das concepções do Pós-modernismo, Clara Celina em seu ensaio "As diferentes concepções que o Pós-Modernismo abarca", publicado no site Em Pauta, pontua:

O pós-modernismo não pode ser visto como um sistema cultural unificado e os pensadores que o compõem não necessariamente tratam dos mesmos assuntos. Daí que Foucault fale de novas concepções de poder, dizendo que este se encontra diluído na sociedade atual; Habermas trate da comunicação e apresente a premissa de que a verdade se apresenta através do diálogo; Giddens estude a relação dos indivíduos com as instituições; Pierre Bordieu delimite a Teoria Praxiológica e defenda que teoria e prática se complementam e transformam concomitantemente. Sendo assim, embora o pós-modernismo traga um novo modo de pensar a respeito de como a verdade se constitui e uma perspectiva mais crítica diante do sistema, ele não necessariamente cai em uma relativização completamente desligada dos valores propagados até então, como muito se julga. Isso também se expressa através do fato de que diferentes pensadores lhe atribuem nomenclaturas diversas, não compactuando entre si [...]. É preciso, portanto, que se tenha tato ao se direcionar críticas ao chamado pós-modernismo (CELINA, 2016).

Diante deste panorama, seria relevante que Hooper formulasse sua crítica levando em consideração as questões metodológicas e éticas. Ele deveria fazer seu recorte e apontar a quais vertentes do feminismo - assim como do pós-modernismo - ele tece sua crítica, pois cada corrente parte de referencial diferenciado, ou seja, não são mais do mesmo, como o autor insinua. Os estudos feministas apresentam características próprias de seu tempo, logo, afirmar que não há nada de novo nos estudos recentes é uma forma de deslegitimação dos saberes produzidos nesse campo epistêmico e de produção de 
saber científico. Suas características são tantas que qualquer tentativa de redução pode ser considerada inconsistente e até irresponsável.

Para além da igualdade de gênero, as novas narrativas buscam romper com a misoginia instituída. O movimento também tem por objetivo reconhecer e refutar as opressões sociais que afetam as mulheres. Defende-se direitos políticos, sexuais e sociais, além dos demais direitos humanos. Tais estudos não estão restritos ao campo da denúncia, mas também, problematizam e refutam epistemológica e politicamente as violências consequentes da estrutura patriarcal. Para reafirmar seus argumentos conservadores, Hooper enfatiza: "Cusick, por exemplo, afirma que é muito claro que muitos trabalhos canônicos que representam abertamente as mulheres também representam a misoginia institucionalizada" (CUSICK, 1999, p. 482, apud HOOPER, 2006, p. 20).

Vale ressaltar que nem sempre falar numa perspectiva histórica sobre produções de mulheres se caracteriza num estudo feminista. As abordagens históricas nesses estudos são tão legítimas quanto em qualquer outro, pois a contextualização histórica não é uma exigência aos trabalhos onde tais articulações são relevantes? Por isso, é questionável enquadrar todos os estudos realizados por mulheres e/ou sobre mulheres como feministas. Mais importantes são os sentidos que se atribuem à contextualização histórica das pesquisas sobre protagonismos de mulheres na música, quando isto se configura como ferramenta para evidenciar o apagamento e as desigualdades na produção de conhecimento das mulheres dentro de uma estrutura sexista e misógina.

É preciso sublinhar que, assim como os homens, as mulheres também são educadas e ensinadas a reproduzir as práticas machistas. Portanto, culpabilizar as mulheres - principalmente aquelas que não participam das construções das pautas feministas bem como aquelas que, de alguma forma, propagam ideias sexistas em seus trabalhos - é uma forma que o autor apresenta para afirmar sua própria misoginia com discursos que foram e são outorgados numa sociedade patriarcal.

No livro Feminine Endings: music, gender and sexuality, a musicóloga Susan McClary faz reflexões em torno da representação musical da bravura masculina e/ou da sedução feminina no filme Indiana Jones, que se assemelham, em muitos aspectos, com aquelas das óperas setecentistas de Cavalli. Estas reflexões confirmam uma narrativa musical consolidada, que se mantém enraizada trezentos anos depois nas telas dos cinemas de todo o mundo. Sobre os argumentos de McClary em Feminine Endings, Hooper faz uma crítica deslegitimando a relevância da obra no campo musicológico ao afirmar que o estudo da autora não apresenta caráter inovador e nem conteúdo para os estudos musicológicos. Como se não fosse o bastante, ele segue afirmando: 
É claro, o exemplo dado pelo New Grove Dictionary of Women Compositors também aponta uma espécie de duplo vínculo em que tais empreendimentos quase inevitavelmente se encontram: eles correm o risco de reinscrever a própria distinção que estão tentando apagar - em suma. Não existe Dicionário New Grove de compositores masculinos. O ponto mais fundamental, no entanto, é que, de uma perspectiva metodológica, não há nada particularmente "novo", "crítico" ou "pós-moderno em ampliar o domínio da música considerado" elegível "ou" apropriado ao estudo musicológico para incluir o composto por mulheres (HOOPER, 2006, p. 21).

Argumento como este revela nada mais que um pensamento de quem não está inteirado sobre as pautas feministas, nem atento ao que as mesmas chamam de "pensar os próprios privilégios". A citação incita vários questionamentos e alguns deles são: a qual perspectiva metodológica o autor se refere? O que ele chama de "novo" e crítico? Qual é a sua perspectiva de Pós-moderno? O que ele considera elegível ou apropriado ao estudo musicológico? Haveria apenas uma única maneira de abordagem dos estudos musicológicos? Pensaria o autor que o seu ponto de vista é o único passivo de legitimidade?

A defesa pela afirmação da dimensão humana a partir da presunção de um ser humano universal (que o faz construir sua crítica sobre New Grove Dictionary of Women Composers) é algo refutado nos movimentos feministas. Não nos esqueçamos que os espaços de poder sempre foram de dominação masculina, o que tornaria a criação de um New Grove de compositores masculinos uma ação prolixa voltada à finalidade de insuflar o ego dos compositores inseguros. Talvez personagens como o autor aqui citado precisem ostentar seus privilégios para se sentirem superiores às mulheres e demais grupos marginalizados.

\section{A construção das narrativas}

Historicamente, há muitos casos em que homens compositores ou instrumentistas assinam como "autores" das obras musicais compostas por mulheres de suas famílias. Do século XVII até o XX, mulheres foram invisibilizadas no campo musical e continuam sendo hoje - com algumas variações. Podemos citar alguns nomes como por exemplo, Fanny Mendelssohn, Clara Schumann, Alma Mahler, dentre outras.

No caso das mulheres negras, há um silenciamento imperativo. São poucos os estudos que falam sobre os protagonismos de musicistas negras, sendo as documentações em que se encontram registros sobre o assunto referentes ao período colonial, muitos deles relatos de europeus viajantes. O racismo patriarcal heteronormativo, unido ao classismo e demais marcadores de opressões, criou e disseminou discursos e ações que excluem as mulheres negras dos espaços de poder em 
todas as instâncias da sociedade. Porém, já é de conhecimento público nomes de várias musicistas negras. Nireu Cavalcanti, em "O Rio de Janeiro Setecentista: vida e a construção da cidade da invasão francesa até a chegada da Corte", referencia dez nomes de cantoras/atrizes negras que atuavam nos palcos do Rio de Janeiro:

\begin{abstract}
Francisca de Assis - 1810 interpretou a "Poesia" na peça "O Triunfo da América"; Francisca de Paula - XVIII, cantora, da Companhia Lírica criada por Antônio Nascente Pinto (A.N.P); [...] Ignês - XVIII, cantora, da Cia. Lírica de A.N.P.; Jenoveva - XVIII, cantora, da Cia. Lírica de A.N.P.; [...] Joaquina Maria Conceição, vulgo 'Joaquina Lapinha' - 1810, atriz e contralto, interpretou a "América" na peça "O Triunfo da América"; [...] Luisa - XVIII, cantora, da Cia. Lírica de A.N.P.; [...] Lobato Maria Cândida - 1810,- atriz, interpretou a "Gratidão" na peça "O Triunfo da América"; [...] Maria Jacinta, vulgo "Marucas" - XVIII, cantora, da Companhia Lírica de A.N.P.; Paula - XVIII, cantora, da Cia. Lírica de A.N.P.; [...] Rita Felicianna - 1810, atriz, interpretou a 'Vingança' na peça 'O Triunfo da América' [...]. (CAVALCANTI, 2015, pp. 580-581).
\end{abstract}

Segundo Budasz, Curt Lange apresenta dois nomes de cantoras líricas negras no século XVIII. "Existem registro de pagamento às cantoras: Ana Joaquina - (4 oitavas) e Violante Mônica (4 oitavas)”. (BUDASZ, 2008, p. 127). Sampaio relata que "o professor Antônio Carlos dos Santos encontrou um documento datado de 1860, contendo cinco nomes de negras dedicadas à música vocal”. Os nomes que ele apresenta são das sopranos: "Leonor Joaquina, Inácia Francisca, Maria da Conceição e das contraltos: Maria Josefa, Bona Luísa” (SAMPAIO, 2008, p. 29).

Em uma consulta no Álbum de Docente do Centenário da Escola Nacional (atual Escola de Música da UFRJ) organizado por Francisco Manoel da Silva e Joanídia Sodré em 1848, encontramos registros de várias professoras e professores de descendência africana lecionando em diversos instrumentos e disciplinas teóricas. Um exemplo é a própria Joanídia Sodré, uma mulher negra que assumiu o cargo de Direção da Escola. Nele aparecem também a professora e intérpretes Camila da Conceição e Izaíra de Oliveira - este é o nome que a cantora assumia publicamente, porém, no registro de ata da Escola aparece Isaíra de Oliveira, dentre vários outros.

O racismo patriarcal heteronormativo se estabelece por hierarquias. Esta é explicada por Lélia Gonzalez (2018, passim), segundo a qual o imperialismo patriarcal eurocristão se constitui em uma estrutura pautada no privilégio social e epistêmico e por isso, as sociedades que sofreram o processo de colonização produzem seus saberes de forma colonizada. Em um modelo hierarquizado na produção de saber, onde o conhecimento ocidental é posicionado como universal, ela aponta a necessidade de descolonização da produção de conhecimento. 
A ideia referencial que gera um contrassenso ao pensamento do musicólogo é o conceito de Lugar de fala. Outro conceito igualmente importante é o de Epistemicídio. Segundo Sueli Carneiro em sua tese de doutorado A Construção do outro como não-ser como fundamento do ser, epistemicídio é um conjunto de intentos por parte da cultura hegemônica instituída que perpassam pela anulação, desqualificação, assim como a produção de discursos de deslegitimação da capacidade cognitiva e intelectual acerca dos povos subjugados por meio das diferentes mídias e mecanismos de anulação do ser do Outro. "É uma forma de sequestro da razão em duplo sentido: pela negação da racionalidade do Outro ou pela assimilação cultural que em outros casos lhe é imposta" (CARNEIRO, 2005, p. 97).

Sobre a lógica patriarcal que modula a linguagem, os discursos e a estrutura musical, Susan McClary utilizou a epistemologia feminista como lente para visualizar, ressaltar e problematizar os discursos que estão argamassados no pensamento e nas práticas da música de concerto. No capítulo Constructions of Gender in Monteverdi's Dramatic Music [Construção de Gênero na Música Dramática de Monteverdi] ela destaca que desde o século XVII compositores enfrentam problemas no campo da representação sobre o masculino e feminino no campo da música dramática, principalmente na ópera. "É possível traçar alguns dos sinais musicais para a masculinidade ou feminilidade que são exibidas na ópera indo de volta a gêneros anteriores, como o Madrigal" (MCCLARY, 1991, p. 36).

Ela avalia que a ópera é influenciada pelo conteúdo erótico que se configura como a temática central do repertório madrigalesco. Nos madrigais, as subjetividades, os desejos e as paixões masculinas expressavam a narrativa dominante da cultura ocidental. Para a autora, a ópera se configura no principal meio de propagação da ideia ocidental de gênero e sexualidade. Em L'Orfeo, segundo McClary, Monteverdi criou a retórica da sedução.

Um processo de excitar artificialmente as expectativas e, em seguida, deliberadamente canalizar os desejos dos ouvintes. O sexy, arrogante e carismático Orfeo é melhor ilustrado em seu primeiro enunciado - a canção de casamento "Rosa del Ciel." (MCCLARY, 2002, p. 39).

Ela demonstra também como Monteverdi construiu na personagem feminina Proserpina a retórica da sedução dentro de uma lógica patriarcal e autoritária.

Naomi André afirma que na ópera Carmen, de Bizet, visualizamos os códigos tradicionais de masculinidade na personagem de Dom José. Quando Carmen se volta para ele, Dom José se torna cada vez mais incapaz de resistir às suas exigências e 
encantos. Quando ela o refuta e afirma que não o ama mais, seu desespero aumenta, fica mais doloroso e ele se transforma em bandido.

\begin{abstract}
Ao contrário da independência de Carmen, em que ela permite a todos e, mais importante, a si mesma tomar suas próprias decisões, apesar da pressão para atender às convenções, Don José perde o controle de suas ações e seu senso interior de justiça. Procedendo sem uma base moral, ele apaga efetivamente seu próprio desejo de seguir em frente. Suas palavras finais, que concluíram a ópera, mostram sua capitulação à autoridade que ele acabara de desconsiderar e sua consequente admissão de culpa: "Você pode me prender, fui eu quem a matou (ANDRÉ, 2016, p. 124).
\end{abstract}

Ela sublinha que muitas dessas versões sobre Carmen apresentam uma perspectiva que naturaliza o medo acerca de estrangeiros e promove a internalização de ideologias racistas.

\title{
6. Dos estudos interseccionais
}

Tecemos nossas considerações ao conceito de "Interseccionalidade" na perspectiva da Kimberle Crenshaw e Lélia Gonzalez. Para Kimberle Crenshaw, "[A] interseccionalidade visa incluir questões raciais nos debates sobre gênero e direitos humanos e incluir questões de gênero nos debates sobre raça e direitos humanos. Ela procura também desenvolver uma maior proximidade entre diversas instituições." (CRENSHAW, 2002, p. 8). A autora destaca as múltiplas violências das quais as mulheres negras são vítimas: no contexto racial, em que são afetadas pela violência contra xs negrxs, e no contexto de gênero, quando são afetadas pela violência contra as mulheres: "No entanto, quando as leis não preveem que as vítimas da discriminação racial podem ser mulheres e que as vítimas da discriminação de gênero podem ser mulheres negras, elas acabam não surtindo o efeito desejado e as mulheres ficam desprotegidas" (CRENSHAW, 2002 p. 8).

No Brasil, a socióloga Lélia Gonzalez foi uma das principais estudiosas a colocar o conceito de interseccionalidade como campo epistemológico em seus estudos. Em Cultura, etnicidade e trabalho: efeitos linguísticos e políticos da exploração da mulher, ela faz uma reflexão sobre como os marcadores de raça e classe são utilizados pela estrutura econômica e política, onde juntos operam de forma a determinar a classe econômica e a posição social de mulheres negras na sociedade brasileira. A socióloga aponta que o marcador de raça determina o de classe dentro de uma sociedade estruturalmente racista. A estrutura econômica capitalista brasileira, por exemplo, se estruturou a partir da escravidão indígena e negra. Podemos entender então que neste país o capitalismo se mantém por meio da exploração e do racismo, sendo os grupos raciais negro e branco economicamente desfavorecido afetados de forma distinta. Essa 
categoria metodológica é algo relevante para se desnaturalizar essa narrativa negativa sobre as mulheres negras, pois elas formam um dos grupos que sempre foram atuantes na música.

A atuação das mulheres negras no âmbito musical é uma realidade não só comprovada pelo tempo e por documentos históricos, mas pela presença de inúmeras musicistas negras desde o período colonial. Por esta razão Jurema Werneck Pinto, em $O$ Samba Segundo as Ialodês: mulheres negras e a cultura midiática, ressalta a importância dos estudos feministas visto pela perspectiva das mulheres negras, pois, para ela,

a desigualdade social produzida poderia exigir deste segmento particular o desenvolvimento de estratégias [...]. Ou seja, as mulheres negras seriam provocadas a produzir práticas inovadoras que podem resultar em instabilidades, ou mesmo em mudanças do status quo" (WERNECK, 2007, p. 1).

A negação ao reconhecimento da produção artística e intelectual das mulheres negras é algo cada vez mais evidente e indiscutível. Partindo desta constatação, as mulheres negras têm partido do seu lugar de subjugadas para reivindicar reconhecimento como forma de romper com o racismo estrutural e estruturante. Diante de tantos desafios, uma questão relevante no debate sobre feminismo e musicologia/música é a superação dos estorvos históricos arquitetados sob o tabu do debate público em torno do racismo e pela exaltação da miscigenação e do mito da democracia racial. Outra é, também, a que diz respeito ao processo de inovação dos aspectos paradigmáticos das bases epistêmicas, alinhando-se com as novas correntes de produção de conhecimento.

A atual produção de narrativas deve observar, sobretudo, a presença de "novos" sujeitos que antes estavam fora do contexto e que agora não só adentram esse universo, como também questionam as estruturas tradicionais e reivindicam novas práticas. Práticas que promovam experiências não somente de vivência da diferença, mas, principalmente, de protagonismos enquanto agentes produtores de saberes, lugar de fala e representatividade. Refletir sobre o feminismo na musicologia numa perspectiva interseccional, implica diretamente incitar debates sobre os diferentes grupos estéticos, músicas, fazeres musicais, étnicos raciais e locus social, bem como as formas em que cada grupo é atravessado pela estrutura social, considerando os status quo instituído.

\section{7. “Ópera negra”, sem perspectiva negra}


Observando-se o contexto estadunidense e brasileiro, há pelo menos duas óperas que tratam de "estórias"1 sobre personagens negras(os) fictícias(os), criadas por autores brancos. Nos Estados Unidos, George e Ira Gershwin compuseram Porgy and Bess em 1935, enquanto no Brasil o poeta Ildásio Tavares redigiu o libreto da ópera Lídia de Oxum em 1994. Com objetivo de escrever uma ópera negra, Tavares convidou o compositor Lindembergue Cardoso para musicar seu texto. A partir dessas alegorias, os autores reivindicaram para si o status de patronos da identidade negra no campo musical, discurso que tem sido reproduzido pela crítica e pela mídia. Sobre Porgy and Bess a musicóloga Naomi André, uma das que têm estudado a temática de interseccionalidade na obra, afirma:

Desde a sua primeira encenação em 1935, Porgy and Bess teve uma súbita e íngreme reconhecimento como uma ópera. Ajudada pela produção da Grande Ópera de Houston em 1976 e pela produção da Metropolitan Opera em 1985, nas últimas décadas o trabalho finalmente alcançou o status de uma das grandes óperas americanas de todos os tempos (ANDRÉ, 2016, p. 85).

André aponta problemas na concepção de George e Ira Gershwin. Um deles é o fato de os compositores chamarem sua obra de "American folk opera". Embora achasse esse termo positivo, a musicóloga ressalta que todos esses termos já não mais se enquadram na descrição da década de 1930 na sociedade, nos estudos musicológicos e culturais estadunidenses. Ela questiona: O que era música americana nessa altura da história? A que a palavra "folk" se refere e qual seu significado nos anos de 1930? Antes dos Gershwin, outras(os) compositoras(es) já haviam composto músicas com temas afroamericanos, bem como as(os) próprias(os) compositoras(es) negras(os) que harmonizaram Negro spiritual e outros tipos de músicas.

Parece evidente que o Spirituals e a música negra nessa época tinham algo central a ver com a identidade americana. Vemos líderes na imprensa branca e negra, bem como a primeira geração de compositores americanos nas viradas do século XIX até o século XX, sendo atraídos para vários repertórios da música negra (ANDRÉ, 2016, p. 94).

Naomi André problematiza a concepção de "folk" utilizada por George Gershwin, uma vez que o compositor afirma ter escrito seus próprios spirituals e canções folclóricas. Para ele, Porgy and Bess traz uma música folclórica real, embora de sua autoria. Em artigo, o compositor de Porgy and Bess escreveu:

Desde a abertura de Porgy and Bess, tenho sido perguntado frequentemente por que é chamado de ópera folclórica. A explicação é simples. Porgy and Bess é um conto popular. Seu povo naturalmente

${ }^{1} \mathrm{O}$ termo estória (com "e") é aqui utilizado em tom provocativo, aludindo à antiga prática de empregar a palavra história (com "h") somente quando se tratava de relatar fatos reais do passado. 
cantava música folclórica. Quando comecei a trabalhar na música, decidi contra o uso de material folclórico original porque queria que a música fosse toda de uma peça. Por isso eu escrevi meus próprios espirituais e folksongs. Mas eles são música folclórica real - e, portanto, estando em forma de ópera, Porgy and Bess se torna uma ópera folclórica (GERSHWIN, apud ANDRÉ, 2016, p. 95).

Sobre essa afirmativa, a musicóloga enfatiza que Gershwin parece não ter coerência sobre o seu entendimento do termo. Segundo a autora, "parece estar dizendo duas coisas: que a música é música folclórica de verdade, mas que escreveu suas próprias canções folclóricas originais”. A respeito das críticas de vários estudiosos ao compositor, ela diz que:

Richard Crawford escreve sobre essa afirmação como um exemplo de "fakelore", um termo cunhado por Richard Dorson em 1950, no qual os "dados brutos do folclore [são falsificados] por invenção, seleção, fabricação e processos similares de refinamento para ganho capitalista (ANDRÉ, 2016, p. 95/96).

Além disso, a musicóloga destaca que há vários pontos de discussão em torno de Porgy and Bess que são predominantes na literatura, como as questões de gênero e de raça. A ópera reforça o estereótipo sobre a sexualidade da mulher negra, bem como nuances racistas. Na mesma linha segue a "ópera negra brasileira” Lídia de Oxum, de Ildásio Tavares e Lindembergue Cardoso, em que um dos objetivos era também tratar das questões identitárias raciais brasileiras. Porém, o libretista tematiza as questões identitárias brasileiras por meio de provocações, a partir de uma perspectiva essencialista e baseada na estrutura racial dos Estados Unidos. Naquele país, a estrutura racial se pauta na origem - genótipo - enquanto no Brasil a estrutura é baseada no fenótipo - de marca. Além disso, a trama é contextualizada numa construção de escravidão do século XIX.

A ideia de uma modernidade que promove e celebra a miscigenação e a democracia racial é o fio condutor das concepções dos autores de Lídia de Oxum. Assim, eles colaboram com a criação de um imaginário de inclusão e de uma sociedade igualitária, onde os diversos grupos étnico/raciais, opressor e oprimidos, vivem harmonicamente. Visualizamos na obra a naturalização de estigmas e estereótipos sobre a sexualidade da mulher negra e a desigualdade de gênero.

Fazendo um paralelo entre a obra de Gershwin, à qual Tavares tece duras críticas, pode-se afirmar que Lídia de Oxum carrega problemas semelhantes aos da ópera estadunidense. Tavares acusou George e Ira Gershwin de reproduzirem os estereótipos de A Cabana do Pai Tomás, escrito por Harriet Beecher Stowe em meados do século XIX. Porém, a mesma ideia de negro "subserviente" se projeta em Lídia de Oxum, 
evidenciando que Porgy and Bess, A Cabana do Pai Tomás e Lídia de Oxum são peças do mesmo quebra-cabeças, apesar do distanciamento temporal. Uma produção que ilustra o pensamento racial da colonização, deveras introjetado nas sociedades colonizadas e que se faz dominante por meio das elites escravocratas.

\section{8. Ópera, raça, gênero e representação: perspectivas negras}

Ao contrário da presunção de Tavares e Gershwin, cujas obras narram ideais e fantasias romantizadas, há outras óperas e autoras(es) negras(os) que representam a história, os desejos e a cultura negra. Entretanto, tais obras e autoras(es) são invisibilizadas(os) pela supremacia branca patriarcal capitalista, que sempre se apropriou da cultura de grupos marginalizados para consumação de suas necessidades sejam estas de caráter financeiro, sexual e/ou derivadas da crise Ocidental.

A ópera Trouble Island, composta pelo afro-americano William Grant Still em 1949, é considerada a primeira ópera a ser produzida no Teatro de Ópera de Nova York. A dramaturgia narra fatos históricos dos principais líderes dos levantes pela independência do Haiti, por ser este país, o primeiro do Continente americano a abolir o sistema escravagista.

$\mathrm{Na}$ África do Sul, país que tem lançado atualmente no campo operístico mundial grandes intérpretes, também há compositores negros disputando as narrativas no campo da representação da identidade cultural negra. Escrita em Zulu, a ópera Princess Magogo kaDinuzulu do compositor sul-africano Mzilikazi Khumalo, escrita em 2002, fala da história da princesa Constance Magogo kaDinuzulu. Ela era compositora de música clássica e cantora, e enfrentou as estruturas de opressão da África do Sul.

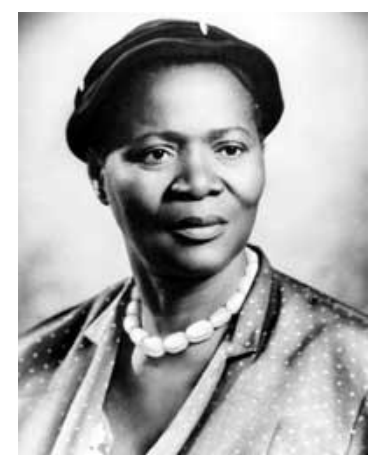

Figura 1: Princess Magogo - Zulu Princess. Foto disponível em: South African History Online ${ }^{2}$

\footnotetext{
2 Princess Magogo | South African History Online. Disponível em: https://www.sahistory.org.za/people/princess-magogo. Acesso em: 16/ 05/2019 às 22:17 hrs.
} 
Segundo a matéria "Ravinia kicks off centennial with story of Zulu princess", do Chicago Tribune, a ópera foi estreada nos EUA no Ravinia Festival 2004, em Chicago. 3 "Princesa Magogo kaDinuzulu, teve um grande sucesso em sua estréia mundial em maio de 2002, na cidade irmã de Durban, em Chicago [..], foi transmitida ao vivo pelos EUA e pelo mundo através das instalações da estação de belas artes de Chicago WFMT-FM 98.7" (CHICAGO TRIBUNE, 2004).

Por sua vez, o compositor Bongani Ndodana-Breen escreveu o texto musical da ópera Winnie: The Opera, com libreto de Warren Wilensky e Mfundi Vundla. O drama conta, por meio de um roteiro adaptado, a história de vida de Winnie Mandikizela Mandela. A estreia mundial, que foi encenada para a própria Winnie Mandela no State Theatre de Pretoria em 28 de abril de 2011, teve a direção de Shirley-Jo Finney e regência de Jonas Alber. A cantora lírica Tsakane Maswanganyi interpretou a protagonista Winnie Mandela. Após a apresentação Winnie Mandela fez um discurso, no qual não somente endossou a relevância da obra, como também elogiou as lutas políticas pela soberania da África do Sul e as pautas antirracistas.

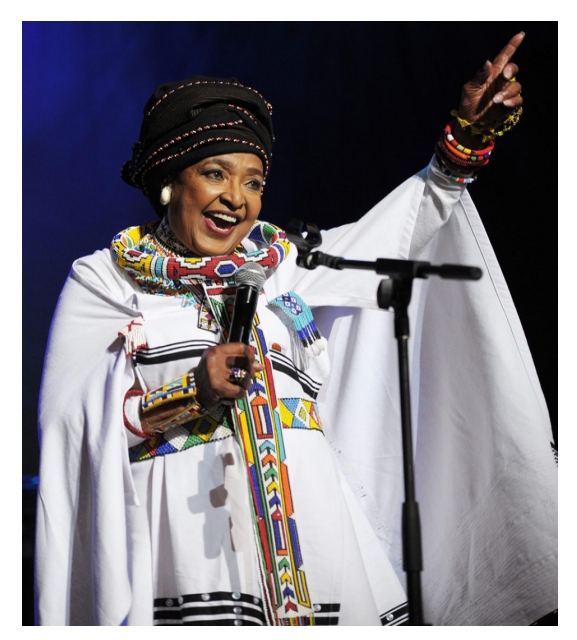

Figura 2: Winnie Madikizela - Mandela. Foto disponível na internet.

Segundo Naomi André, “Winnie: The Opera não é uma ópera que simplesmente mostra um esforço de boa fé. Winnie é uma produção que pertence ao repertório da ópera e mostra novas direções para o futuro do gênero" (ANDRE, 2016, p. 182).

\footnotetext{
3 Chicago Tribune: Ravinia kicks off centennial with story of Zulu princess. Disponível em: https://www.chicagotribune.com/news/ct-xpm-2004-05-30-0405300405-story.html. Acesso em: 16/ 05/2019 às 22:18 hrs.
} 


\section{9. Ópera, raça, gênero e composição: perspectivas negras}

O campo da composição na música tradicional de concerto europeia segue uma estrutura social construída sob a dominação masculina. Isso se reflete no cenário contemporâneo quando nos debruçamos sobre questões relacionadas à presença de mulheres neste campo. O difícil acesso a documentos e nomes de mulheres compositoras é, na realidade, fruto de tal estrutura. Mas, longe de ser um imperativo na afirmação da ausência destas compositoras, a ausência de registro aponta para uma negação de sua existência. Trata-se do apagamento de histórias de vidas, e negar história é negar a própria existência dessas mulheres.

Ao fazermos um recorte interseccional de gênero e raça, a situação fica ainda mais difícil. Porém, novamente, isso não significa que não hajam mulheres negras atuando no campo da composição e da produção musical. Toni Morrison, escritora e editora afroamericana, e vencedora do Nobel de Literatura de 1993, escreveu o libreto da ópera Margaret Garner, cuja composição musical foi feita por Richard Danielpour. A ópera tem dois atos e baseia-se na vida da escrava fugitiva Margaret Garner. Morrison explora a pauta da liberdade, relações pessoais e comunitárias. Músicas da tradição afroamericana religiosa também são utilizadas.

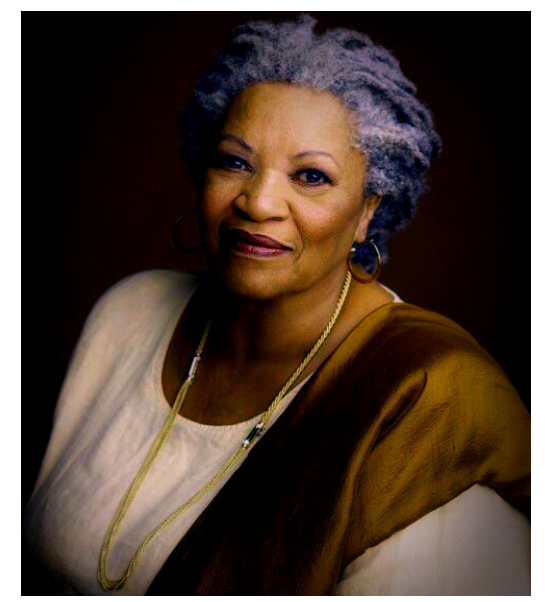

Figura 3: Toni Morrison. Foto: disponível na internet

No artigo Margaret Garner: The Premiere Performances of Toni Morrison's Libretto, La Vinia Delois Jennings, ${ }^{4}$ professora de humanidades, literatura e cultura americana do século XX na Universidade do Tennessee, traz dados que comprovam a vida de Margaret Garner:

\footnotetext{
${ }^{4}$ Disponível em: https://www.upress.virginia.edu/title/50oo. Acesso em: 16/ 05/2019 às 22:38 hrs.
} 
Em janeiro de 1856, Margaret Garner - uma mulher escravizada em uma plantação de Kentucky correu com membros de sua família para o estado livre de Ohio. Enquanto os caçadores de escravos tentavam capturar os fugitivos em Cincinnati, Garner cortou a garganta de sua filha de dois anos e meio para impedir seu retorno à escravidão (JENNINGS, 2016, University of Virginia Press).

Angela Davis, no livro Mulheres, Raça e Classe também faz referência à história de vida desta ex-escravizada:

Pode-se compreender melhor agora uma pessoa como Margaret Garner, escrava fugitiva que, quando capturada perto de Cincinnati, matou a própria filha e tentou se matar. Ela se comprazia porque a menina estava morta: "assim ela nunca saberá o que uma mulher sofre como escrava" e implorava para ser julgada por assassinato: "Irei cantando para a forca em vez de voltar para a escravidão" (DAVIS, 2016, pp. 33-34).

Toni Morrison já havia escrito sobre Margaret Garner no romance Beloved (1987), vencedor do Prêmio Pulitzer em 1988, quando foi convidada por Richard Danielpour para elaborar o libreto da ópera que ele desejava produzir. Ao contrário dos autores de Lídia de Oxum e Porgy and Bess, Danielpour entendeu que o exercício da escuta seria o fator central para a criação de uma obra que representasse a história de um grupo do qual ele não fazia parte. Talvez este tenha sido o diferencial que garantiu o sucesso da obra, apontada por La Vinia Delois Jennings como "Uma Nova Ópera Americana, cujo mundo estreou em Detroit em 2005” (JENNINGS, 2016).

A compositora cubana Tânia Leon ${ }^{5}$ compôs o texto musical e o libreto da ópera Scourge of Hyacinths em 2005. O texto poético é baseado em Samarkand - uma peça de autoria do escritor e dramaturgo nigeriano premiado com o Nobel de Literatura, Wole Soyinka. A ópera foi encomendada em 1994 pela Bienal de Munique, onde ganhou o Prêmio BMW como melhor nova ópera do festival. A obra retrata um contexto na África e conta a história de um preso político, cuja tentativa de fuga é frustrada. Apresenta um grande lirismo e ricos timbres instrumentais afro-latinos. Em 2001 a peça recebeu três apresentações durante o Festival Centro Histórico na Cidade do México. A compositora, que utiliza técnicas da música contemporânea ocidental, foi diretora e compositora do Dance Theatre of Harlem. Foi também responsável pela direção musical de The Wiz, na Broadway, e pelo ensino de composição no Brooklyn College.

\footnotetext{
${ }^{5}$ Link do site da Tânia Leon: http://www.tanialeon.com/bio.html. Acesso em: 16/o5/2019 às 22:50 hrs.
} 


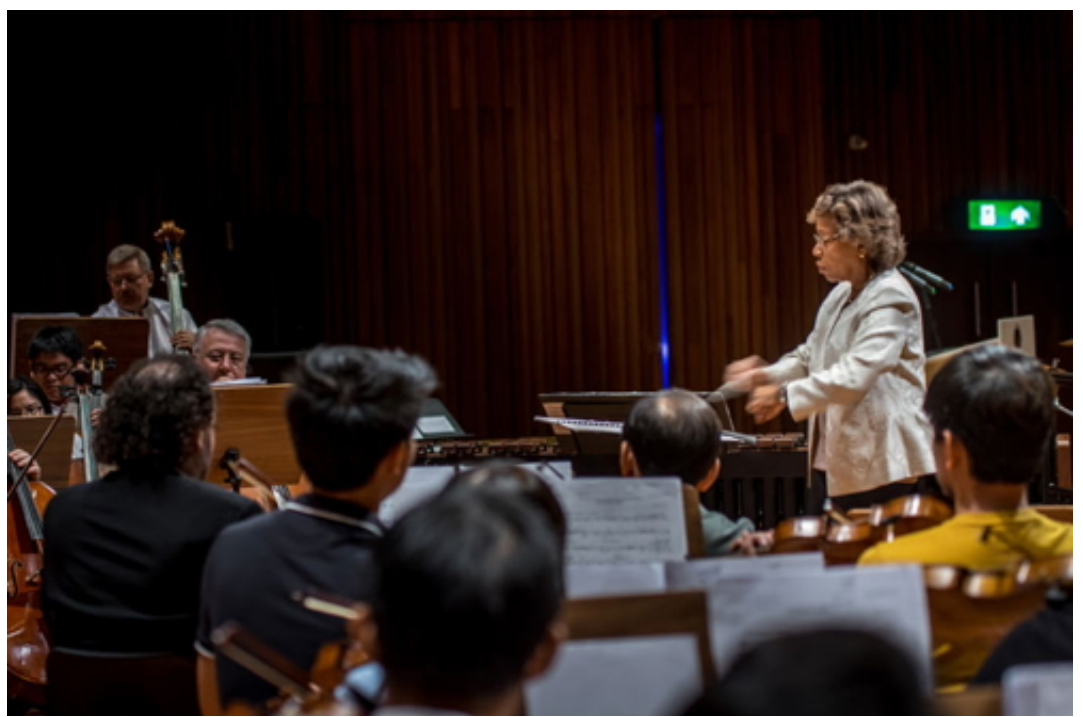

Figura 4: Tania León. Foto: disponível na internet.

\section{Considerações preliminares}

A partir da observação dos fenômenos da colonização que se baseiam em elementos como racismo e patriarcalismo, mostramos como tais estruturas de opressão operam de forma impactante e decisiva na definição de lugares, no acesso e no fazer musical. Pensando nas condições de homens e mulheres negras, estas questões assumem proporções preponderantes.

Mostramos também que o racismo individual, bem como o institucional e o estrutural, propiciam que a opressão de raça se configure no mito fundante dos critérios e parâmetros das relações pessoais, profissionais e sociais. Uma vez que as relações são orientadas pela lente do racismo, torna-se inevitável a marginalização de quem não compõe o grupo posicionado como humano na sua totalidade.

Sendo assim, Locus sociais distintos são estabelecidos de forma que cada grupo racial vivenciará de forma específica e particular as normas que lhe forem impostas. Cada grupo terá seu lugar de fala relativizado pelas regras formuladas por uma sociedade sustentada pela dominação patriarcal, ficando, portanto, suscetível à autorizações discursivas que determinam quem pode falar.

A autorização discursiva é uma das razões que faz com que musicólogos como Giles Hooper se sintam à vontade para deslegitimar o feminismo e os estudos de gênero enquanto campo epistemológicos. Essa mesma autorização discursiva fez com que George e Ira Gershwin, assim como Ildásio Tavares e Lindembergue Cardoso, 
reivindicassem para si o status de patronos da promoção de identidades culturais negras, inclusive, desqualificando intelectuais e expressões culturais negras.

\section{Considerações intermediárias}

Tudo isso nos permite refletir sobre como, dentro desta estrutura de dominação racial e patriarcal, os conceitos e termos são desconectados de seus contextos e utilizados como instrumentos de alienação e dominação do outro. Um exemplo a ser citado aqui é a ideia de "ópera negra", cujo significado não está evidenciado. Será que o fato de alguém tratar de questões afirmando, supostamente, ilustrar "os negros", basta para se afirmar que tal questão é negra?

Observamos, também, como o termo "negros" vem sendo compreendido e utilizado por pessoas e culturas hegemônicas. Após muitos debates, o termo foi escolhido pelo Movimento Negro Brasileiro como categoria identitária política, a partir da definição sistematizada pelo sul-africano Stephen Bantu Biko, para quem ser negro é, "em essência, a percepção pelo homem negro da necessidade de juntar forças com seus irmãos em torno da causa de sua atuação - a negritude de sua pele - e de agir como um grupo, a fim de se libertarem das correntes que os prendem em uma servidão perpétua (BIKO, 1971, UNEB). Biko foi um dos grandes ativistas da luta anti-apartheid na África do Sul, nas décadas de 1960 e 1970.

Segundo Biko, ser negro ou negra significa lutar contra a ideia de que pessoas descendentes de africanos e africanas são apenas apêndices dos brancos e/ou brancas. $\mathrm{O}$ ativista vê neste termo a capacidade de contestar a suposta inferioridade das pessoas negras, o paternalismo das brancas, bem como os processos de branqueamento; conferindo à comunidade negra um reconhecimento de sua negritude positivada e a emancipação no combate à violência simbólica. Ou seja, a definição de negro passa, necessariamente, pelas experiências e vivências de pessoas negras. Logo, se óperas como Porgy and Bess e Lídia de Oxum não levam em consideração o lugar de fala das pessoas negras, não podem ser consideradas mais que "estórias" criadas por pessoas que possuem autorização discursiva.

Ao levantar pontos como os aqui discutidos, ressaltamos que não é nossa intenção censurar qualquer abordagem sobre as questões da negritude na ópera ou em quaisquer outras expressões artísticas. Queremos, sim, problematizar o padrão corrente de representação, que serve apenas para manter o status quo instituído, reproduzindo racismo, estigmas e estereótipos de pessoas negras. Ora, existem artistas negras(os) que atuam neste campo e que, para assumir plenamente sua humanidade negra, precisam se 
ver representadas(os) e às suas culturas. Não abordar elementos da cultura negra é também uma forma de promover o racismo.

O que se reivindica aqui é uma mudança na perspectiva e numa retórica que já não cabe na sociedade atual (ainda que tenhamos consciência de que muitos valores conservadores estejam, ultimamente, sendo resgatados por pessoas e/ou entidades representantes do poder). Para colaborar com tal mudança gostaria de ressaltar, no campo da música, as óperas que podem ser consideradas negras a partir da definição de Steve Biko. Ao contrário das obras citadas na parte inicial deste texto, que servem para reprodução de estereótipos acerca da população negra, os dramas escritos por autoras(es) negras(os), evidenciam o quanto tais perspectivas se distanciam do pensamento colonial escravagista. As obras de autoras(es) negras(os) atuam dentro de um contexto de disputa de narrativa e fazem abordagens críticas, exercendo o ativismo político.

\section{Considerações finais}

As(os) artistas negras(os) utilizam a arte como instrumento para falar de questões estruturais da sociedade. Isso pode ser observado com certa facilidade, uma vez que as obras ou se baseiam em fatos reais, ou tratam de pessoas negras que, embora desfrutem de carreiras sólidas, mesmo assim são invisibilizadas. É praticamente inexistente a divulgação destas obras, ao mesmo tempo em que há um vasto registro de óperas como Porgy and Bess em publicações sobre ópera negra. O silenciamento do protagonismo de negros e, especialmente, de negras, é consequência tanto do racismo quanto do sexismo, já que as obras dos autores negros, ou falam de mulheres negras, ou foram compostas pelas mesmas. Para colaborar com tal mudança gostaria de ressaltar, no campo da música, as óperas que podem ser consideradas negras a partir da definição de Steve Biko.

\section{Referências}

ALMEIDA, Silvio. O que é racismo estrutural? Belo Horizonte: Letramento, 2017.

ANDRÉ, Naomi. Black Opera: History, Power, Engagement. Illinois: University of Illinois Press, 2018.

BIKO, Bantu S. A Definição da Consciência Negra. Salvador: Núcleo de Estudantes Negras "Ubuntu”, Universidade do Estado da Bahia - UNEB, 1971.

BITTENCOUTT-SAMPAIO, Sérgio. Música. Velhos Temas. Novas Leituras. $2^{\mathrm{a}}$ ed. Rio de Janeiro: Mauad, 2016.

BUDASZ, Rogério. Teatro e música na América Portuguesa: convenções, repertório, raça, gênero e poder. Curitiba: DeArtes UFPR, 2008. 
CAVALCANTI, Nireu. O Rio de Janeiro Setecentista: vida e a construção da cidade da invasão francesa até a chegada da Corte. Rio de Janeiro: Zahar, 2004, Ed. Digital, 2015.

CARNEIRO, Aparecida Sueli. A construção do outro como não-ser como fundamento do ser. Tese (Doutorado em Educação). São Paulo: USP, 2005.

CELINA, Clara. As diferentes concepções que o Pós-Modernismo abarca. Em: Pauta. Disponível em: https://wp.ufpel.edu.br/empauta/2016/10/as-diferentes-concepcoesque-o-pos-modernismo-abarca/.

COLLINS, Patrícia H. Blackfeminist thought: knowledge, consciousness and the politics of empowerment. New York: Routledge, 2000.

DAVIS, Angela Y. Mulheres, Raça e Classe. São Paulo: Boitempo, 2016.

Dossiê Mulheres Negras. "A situação dos direitos humanos das mulheres negras no Brasil: violência e violações”. Geledés - Instituto da Mulher Negra e Criola. Org. de Mulheres Negras, 2016.

GONZALES, Lélia. Primavera para as rosas negras: Lélia Gonzalez em primeira pessoa. Coletânea Organizada Ed. UCPA. Rio de Janeiro: Diáspora Africana, 2018

HOOPER, Giles. The discourse of musicology. Aldershot: Ashgate, British Library, 2006.

MCCLARY, Susan. Feminine Endings: Music, Gender, and Sexuality. Minnesota: University of Minnesota Press, 2002.

RIBEIRO, Djamila. O que é lugar de fala? Belo Horizonte: Letramento, 2017.

WERNECK, Jurema P. O Samba Segundo as Ialodês: mulheres negras e a cultura midiática. Rio de Janeiro: UFRJ, 2007. 